\title{
Semanticização e discursivização das construções condicionais no português popular falado na cidade de São Paulo
}

Celso Massato Kobashi*

RESUMO: Este trabalho trata dos processos de Semanticização e Discursivização das construções condicionais no português popular falado na cidade de São Paulo. Tendo como base a Abordagem Multissistêmica da Lingua (Castilho, 2010) e a Linguística Funcional, realizo uma análise qualitativa, abordando os principais aspectos semânticos (condicionais reais, irreais e eventuais; implicativas, epistêmicas, entre outras nuances) e discursivos pertinentes às construções hipotéticas.

Palavras-chave: construções condicionais, semântica, discurso, português popular, Abordagem Multissistêmica da Língua, Linguística Funcional.

\begin{abstract}
The subject of this paper is Semanticization and Discursivization processes in conditional constructions in the vernacular Portuguese spoken in the city of São Paulo. Based on the Multisystemic Approach to Language (Castilho, 2010) and on Functional Linguistics, my analysis is qualitative, addressing the main semantic aspects (real, unreal, eventual; implicative, and epistemic conditional, among other nuances) and discursive aspects relevant to hypothetical constructions.
\end{abstract}

Keywords: Conditional Constructions, Semantics, Discourse, Vernacular Portuguese, Multisystemic Approach to Language, Functional Linguistics.

Introdução

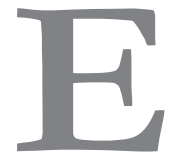

ste trabalho tem como objetivo realizar uma análise qualitativa das construções condicionais nos domínios da Semântica e do Discurso.

* Universidade de São Paulo. celsombo@usp.br 
O corpus analisado pertence Projeto Português Popular em São Paulo e é formado por 30 inquéritos de informantes adultos, homens e mulheres, paulistanos e também migrantes do interior de São Paulo e de outros estados brasileiros, de escolaridade nula ou semi-escolarizados (isto é, que cursaram até o $4^{a}$ ano do primário), e que residem em favelas da cidade de São Paulo..

A análise apóia-se na Abordagem Multissistêmica da Lingua (Castilho, 2010) e na Linguística Funcional.

Haiman (apud Neves, 1999) aponta que não há uma definição satisfatória, nem filosófica, nem linguística, para as construções condicionais; na falta de tal definição, o único critério para a identificação dessas construções é a forma superficial: no caso do português, a conjunção se (ou equivalentes). Geraldi (1978) indica que os "enunciados condicionais" têm como forma se S1, S2.

A questão a se responder neste trabalho é: quais as principais características semânticas e discursivas das construções condicionais no português popular falado na capital paulista?

Semanticização e Discursivização são processos de criação e mudança linguísticas presentes na proposta elaborada por Castilho (2010), que contempla a língua como um conjunto multissistêmico. $\mathrm{O}$ autor postula que a língua pode ser vista como um sistema composto de produtos e processos. Os produtos têm suas propriedades dispostas nos subsistemas da Gramática, do Léxico, da Semântica e do Discurso, e os processos dividem-se entre gramaticalização, lexicalização, semanticização e discursivização. Os produtos e os processos baseiam-se em princípios sociocognitivos. Eles se articulam simultaneamente, multilinearmente e dinamicamente pelos princípios de ativação, reativação e desativação de suas propriedades.

O princípio de ativação refere-se ao movimento mental em que propriedades lexicais, gramaticais, semânticas e discursivas são selecionadas. A reativação é a retomada dessas propriedades, através de procedimentos como a correção e a paráfrase, e a desativação corresponde ao 'silêncio' ou abandono de estratégias que estão em curso.

No caso das condicionais, esses princípios assim se realizam:

(01) Doc cachorru cumia? / Inf cumia... si dexá/ si dexassi elas cho/ botá $i$ chocá nu chão... num ficava um.. intão tinha qui pô nu altu $(B-8 b)$

(02) ah lá:... num num era nada di bom pra mim... si eu fô contá... (O - 16b) 
Em (1), a informante lança mão de uma condicional (ativação) e, logo em seguida, realiza uma série de correções (reativação), antes de completar o seu enunciado. Em (2), ocorre a desativação: a condicional é o meio pelo qual o falante indica que não pretende prosseguir no tópico.

1. Semanticização das construções condicionais

Os trabalhos de Neves $(1999,2000)$ mostram que em uma construção condicional a "proposição" subordinada é chamada prótase (entidade $p$ ) e a principal, apódose (entidade q). Diz-se que tal construção apóia-se numa hipótese, daí a denominação período bipotético. A relação que se instaura entre os conteúdos da prótase e da apódose é uma relação do tipo condição para realização $\Leftrightarrow$ consequência / resultado da resolução da condição enunciada. O resultado se resolve em realização, ou não realização, ou eventual realização.

Assim sendo, nota-se a formação de três tipos de construções condicionais, a saber:

a) Reais - dada a realização, a verdade da prótase, segue-se, necessariamente, a verdade da proposição contida na apódose:

(3) tá muitu bonitu lá... mais si CHOvi é aquela lamera... si si é sol é aquela puera... intão pur inquantu pur inquantu num dá pa $(\mathrm{D}-10 \mathrm{~b})$

b) Irreais - dada a não realização, a falsidade de $p$, segue-se, necessariamente, a não realização, a falsidade de $q$ :

(4) mais nervosu num é tantu... si fossi assim a genti brigava na rua (E - 11a)

(5) "não... si você fossi minha filha era uma coisa... mais cê num é minha FI::lha tá aqui nu meus cuiDA::du" $(\mathrm{X}-21 \mathrm{a})$

c) Eventuais - dada a potencialidade de $\boldsymbol{p}$, segue-se a eventualidade de $q$.

(6) daí eu falei assim "si pai i mãe querê ieu queru" (K 14b) 
(7) compru nas casa revendedora né?... ( ) mais talveiz si eu fossi na fábrica era mais baratu né?... (F - 14a)

A existência dos três grandes grupos - real, irreal e eventual - nos quais se distribuem as orações condicionais não é suficiente para a compreensão mais profunda do período hipotético, visto que, como ressalta Neves, o uso linguístico efetivo dessas construções não reflete pura e simplesmente a noção de "condição-consequência", expressa na fórmula lógica se... então,

Em Kobashi (2004), trabalhei com toda diversidade de nuances envolvendo as condicionais ${ }^{1}$. Neste texto, retomo a maior parte dessas nuances, de forma mais concisa.

Sweeetser (apud Neves, 1999) destaca três tipos de construções condicionais: as de conteúdo ou implicativas ${ }^{2}$, as epistêmicas e as "de ato de fala". As duas primeiras expressam relações lógico-semânticas e a última pertence ao campo pragmático e será tratada na seção destinada à discursivização das condicionais.

As condicionais de conteúdo: são construções que abrigam a noção de "realização no mundo real", na apódose, dependente de uma "condição suficiente" na prótase. Nesse tipo de construção, existe mais concretamente uma relação causal. Aqui, relacionam-se dois estados de coisas: um estado de coisas motiva a realização de outro.

(8) ah... purque é mais siguru né? num tem pobrema di tá pinganu quandu cho:vi... si a pessoa tacá pedra num quebra a telha... essis negóciu todu né? $(4-4 a)$

(9) elis robava i vendia ainda pra... vizinhu mais... vendia i num tava nem aí... i si a genti fossi fazê reclamação né? ia puxá revolvi ... pu maridu da genti... tudu issu... $(\mathrm{O}-16 \mathrm{~b})$

\footnotetext{
Nuances de natureza semântica (implicação, ressalva, habitualidade, entre outros, pragmática (condicionais de ato de fala, dialógicas) e até mesmo sintática (condicionais inversivas) (Cf. Kobashi 2004, pp. 63 e seguintes)

2 Geraldi (1978) as denomina de implicativas, pois nessas construções, há uma implicação entre os conteúdos da prótase e da apódose
} 
(10) na primera veiz cê fala "Ó... si num qué mi obedecê podi sumí cum teus

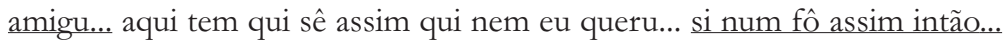
suma"... mais si acoita. $(\mathrm{P}-17 \mathrm{a})$

Nos exemplos acima, destaca-se a relação de "causa (ou condição) e consequencia" que se estabelece entre os conteúdos da prótase e da apódose. Na segunda oração de (10), o falante lança mão da fórmula "Se... então", o que explicita por completo esta relação.

As condicionais epistêmicas são aquelas nas quais o que se expressa é a idéia de que o conhecimento da verdade da premissa hipotética expressa na prótase é uma condição suficiente para se deduzir a verdade da proposição expressa na apódose. Aqui não se relacionam simples "estados de coisas" (predicações), e, sim, proposiçoês. Isso significa que aquilo que está expresso na apódose é uma conclusão a que levou a proposição expressa na prótase. Pode ser resumida na fórmula "SE p, eu concluo q".

(11) si você pricisa di trabalhá... quem vai ficá cum aquela criança? ninguém vai ficá... si você já Pois ali na crechi é purque num tem quem fiqui (T. 19a)

(11a)si você já POis ali na crechi, concluo que num tem quem fiqui

(12) si eli ali é spirita ele senti melhó nu spiritismo $(\mathrm{R}-18 \mathrm{a})$

(12a)si eli ali é spirita, concluo que ele senti melhó nu spiritismo

As paráfrases (11a) e (12a) permitem notar com mais clareza a leitura epistêmica.

Neves (1999) observa que as construções de fórmula "Se... é porque" podem apresentar ao mesmo tempo as leituras implicativa e epistêmica. Seja a mesma ocorrência (11) acima, o enunciado se conduz da seguinte forma:

(11c)

se (já que) você já Pois ali na crechi - enuncia-se um "dado" como verificado; então (em consequência, se conclui que) é (isso ocorre) porque (pela seguinte causa): num tem quem fiqui - ao invés de enunciar-se um fato como implicativo ou conclusivo, traz-se a conclusão no discurso (através do ê) e acrescenta-se a "causa" (porque).. 


\section{Celso Massato Kobashi}

Em casos como (11), as condicionais epistêmicas apresentam "uma causalidade interveniente", que as aproxima das orações implicativas ou de conteúdo.

Além dos valores implicativo e epistêmico, as construções condicionais apresentam outras nuances e sutilezas semânticas, das quais trato a seguir.

1.1 Os subgrupos de construções condicionais

\subsubsection{Condicionais reais / factuais}

As construções reais ou factuais são aquelas que repousam sobre a realidade. O enunciado da prótase é concebido como real, e, então, o enunciado da apódose é concebido como uma consequência necessária, e, portanto, também real. A relação que se instaura entre as orações no período real / factual é a seguinte:

1) enuncia-se a ocorrência de um estado de coisas como preenchimento de uma condição (prótase);

2) a partir daí, enuncia-se um estado de coisas como real / uma proposição como factual (apódose), em consequência do preenchimento daquela condição, como no exemplo abaixo:

(13) intão cê tem si a idéia é boa cê aprendi aprendi fazê quarqué coisa... (C 9b)

Nota-se o caráter implicativo dessa construção em que se lê: "si a idéia é boa implica / resulta [que] cê aprendi aprendi fazê quarqué coisa”.

(14) Doc todu mundu comenta issu né? / Inf si num quisé... si num quisé sê assaltadu o mortu não passa pelu iscadão não...(D - 10b)

(14) ilustra a observação de Mira Mateus et al (1983): o enunciado condicional, neste caso, é uma generalização (um princípio, uma lei) que remete a um "mundo" epistemicamente acessível. Assim sendo, a factualidade é assegurada mesmo com o uso do subjuntivo, modo que denota dúvida, na prótase. 
A fala da informante é um arremate para uma observação da documentadora, que expressa um consenso geral.

Além das leituras implicativa e epistêmica - no exemplo (11) visto anteriormente -, as condicionais reais, apresentam as seguintes relações semânticas:

- Condicionais opositivas e /ou concessivas (Geraldi, 1978): são aquelas que expressam a idéia de contraposição e/ou de concessão, sendo muitas vezes difícil dissociar essas duas nuances. Podem ser parafraseadas pela forma "se por um lado... por outro...".

(15) aquelas mãe si é di cuidá da casa é obrigadu í trabalhá... pra tra/ ajudá aqueli homi... dá conta daquela família... S - 18b)

(16) qui nem aqui... aqui é si si elis sabi passa si não sabi passa du memu jeitu...(E $-11 \mathrm{a})$

Em (16) além da noção implicativa, eis as outras interpretações possíveis:

Contraste (adversativa): Ele não sabe, mas passa do mesmo jeito;

Concessão (concessiva): embora (ainda que) não saiba, ele passa

- Condicionais habituais: (Geraldi, 1978): expressam uma relação implicativa, de caráter habitual, repetitivo. Pode ser parafraseado como: "sempre que p, q".

(17) intão eu... si elis pergunta alguma coisa... sô obrigado a respondê u qui significa... u qui tem nu orçamentu... $(\mathrm{R}-18 \mathrm{a})$

(17a) Sempre que elis pergunta alguma coisa... sô obrigado a respondê u qui significa...

(18) i eu toda vida si eu tenhu qui fazê uma assim... nu intervalu du dia eu levantu cedu pra mim fazê cedu $(2-2 a)$ 


\section{Celso Massato Kobashi}

(18a) Sempre que eu tenhu qui fazê uma assim... nu intervalu du dia eu levantu cedu pra mim fazê cedu

\subsubsection{Condicionais irreais / contrafactuais}

As condicionais contrafactuais ou irreais são aquelas que repousam sobre a não-realidade, apresentando estados de coisas como não-existentes, tanto na prótase como na apódose.

(19) qué dizê é a imbição du dinheru... si nóis nu mundu num tivessi a imbição du dinheru u país era bom... u mundu era bom né? (a - 23a )

(20) ora mais eu não adivinho eu nu adivinhava si eu adivinhassi eu... si eu adivinhassi tinha segurado... mais nu adivinho... $(\mathrm{O}-7 \mathrm{~b})$

A relação mais ampla que se expressa nas construções irreais é a de implicação. Observa-se, porém, que a relação consecutiva, diferentemente do que se dá nas construções reais, ocorre com inversão de polaridade da prótase e da apódose, como se nota em (21) e (22):

(21) elas foi franca cumigu... "ó iara si você falassi nu começu eu talveiz num ficava cum você não purque... a genti tem medu cê sabi qui a genti tem medu"... (D - 10b)

$\left.1 .^{\circ}\right)$ prótase positiva: se você falasse $=>$ pressuposto negativo: você não falou;

$\left.2^{\circ}{ }^{\circ}\right) \quad$ apódose negativa: eu não ficava $c o m v o c \hat{e}=>$ conteúdo asseverado positivo: eu fiquei com você.

(22) agora... qué dizê si eu pricisassi... di meu filhu í pra lá pra escola... num precisassi di de di/ prefeitu/ di:: professora nem diretô da escola... eu num mandava meu filhu pra lá... ( $\mathrm{S}-18 \mathrm{~b})$

$\left.1 .^{\circ}\right) \quad$ prótase negativa: se não precisasse $=>$ pressuposto positivo: precisa;

$\left.2^{\circ}{ }^{\circ}\right) \quad$ apódose negativa: eu não mandava $=>$ conteúdo asseverado positivo: eu mando.

Entre as irreais, insere-se um tipo de construção peculiar, aquele que utiliza a locução como se:: 
(23) vai comu si fossi sua filha" i di FA:tu ela mi tratô comu si fossi minha filha (X -. 21a)

Essa ocorrência se situa na fronteira entre as orações comparativas e as condicionais irreais. Construções como essas geram diferentes posicionamentos por parte dos estudiosos.

Mira Mateus et al. (1983) propõem a seguinte leitura para as sentenças de como se:

(23a) "vai, como iria [= comparação] se fosse [= condição irreal] a sua filha e de fato ela me tratou da mesma forma que trataria se fosse minha filha"

Leão (1961) é frontalmente contrária à reconstituição do verbo supostamente eliptico. Diz ela que "o indivíduo que usa tais construções não tem sentimento da ausência de um verbo: a forma reduzida parece-lhe perfeitamente natural" (p. 109). Para ela, a locução como se possui "unidade semântica, para exprimir uma comparação não quantitativa, sob forma hipotética, com implicação de irrealidade." (p. 110)

\subsubsection{Condicionais eventuais/ potenciais}

Nas construções condicionais eventuais, a prótase repousa sobre a eventualidade. O enunciado da apódose é tido como certo, desde que eventualmente satisfeita a condição enunciada.

(24) eu pretendu... si eu melhorá bem eu pretendu ainda voltá $(2-2 a)$

(25) ah é lógicu... lógicu purque si u papa falá entrá nu meiu falá assim "num/ vai pará issu" eli para... certu? (D -24b)

As construções eventuais são do tipo "implicativo", já que o preenchimento da condição implica no que vai expresso na oração núcleo. Mas, ao contrário do que ocorre nas condicionais reais, essa implicação não significa necessariamente causalidade, como pode ser comprovado em:

(26) cadê a pulícia aqui? si procurá um polícia aqui ninguém encontra... (S- 18b) 
(27) si eu fô chorá num dá jeitu eu tenhu qui surri K - 14b)

Em (26) não é a falta de procura que causa o aparecimento da polícia; já em (27) a vontade de chorar não é o motivo que leva a "não dar jeito"

No entanto, há casos em que existe de fato uma implicação do tipo "causa-consequência":

(28) eu falu todu tempu quandu eu quisé trabalhá si a casa delas num tivé ninguém ainda voltu pra lá (T - 19a)

Em (28), o fato da casa não ter ninguém é a causa doa falante voltar pra lá.

Algumas construções eventuais apresentam outras relações que não a de implicação. São elas:

- Habitualidade, contraposição e concessão:

(29) qui eu nunca fui uma muié assim di isperá u trabalho só deli né? si eu num tava trabaiandu lá fora mais eu arrumava um sirviçu pra mim fazê em casa pra ganhá u dinheru sempri né? $(2-2 \mathrm{a})$

A ocorrência acima possibilita as seguintes interpretações:

(29a) sempre que eu não estava trabalhando fora, eu arrumava serviço pra mim fazer em casa (habitualidade)

(29b) eu não estava trabalhando lá fora, mas eu arrumava serviço pra fazer em casa (contraposição)

(29c) Se por um lado, eu não trabalhava fora, por outro eu arrumava serviço pra fazer em casa. (SE concessivo)

- Ressalva enuncia-se a apódose (o “condicionado"), ou parte dela, para depois enunciar-se o condicionante, do qual depende o que vai expresso na apódose. Com isso, ocorre uma relativização do conteúdo da apódose (ou parte dela) enunciada: 
(30) ah lá é bem mais melhó... incrusivi... nu paraná a genti só compra u u sal... i u açúcar i u açúcar [compra] si quisé qui si num quisé tem cana... (C- 9b)

(31) aí a minha MÃE qui deus (dê u reinu da glória a ela pur achá qui deus si deus achá qui ela mereCÊ) $(K-14 b)$

Em (30), a posposição da condicional realça a importância secundária do açulcar, o que fica claro logo em seguida ("se num quisé açulcar tem cana”). Em (31), a ressalva serve como atenuante do pedido enfático feito anteriormente ("que Deus dê o reino da glória pra ela").

\section{- Condição necessária e suficiente}

(32) agora us filhu já veiu di lá piquenu êlis num... só si fô essi maió essi aí::: podi contá alguma coisa mais agora us otrus num num sabi purque veiu já veiu... piquenu num tem grandis lembranças né? $(\mathrm{Q}-17 \mathrm{~b})$

(33) Inf não... na bahia não num ixistia issu aí não... ih a genti vivia tranquilu lá... a num sê qui... fossi... uma cobra um bichu rúim du matu assim qui pegassi a genti... du contráriu não $(\mathrm{V}-17 \mathrm{a})$

O intercalamento da prótase, em (32), e a posposição (33), indicam que apenas causas muito específicas poderiam alterar os estados de coisas "os outros filhos não têm grandes lembranças", em (32), e "a gente vivia tranquilo", em (33).

- Lembrete (em inglês, afterthought), que reforça o que se disse anteriormente:

(34) uma pessoa qui mora lá pur ipiranga comu pinheru comu osascu comu essis mundu di lá... elis vem praqui pra pegá um rádiu dentru di uma casa? vai pegá uma xícara? vem:: pegá uma criancinha estupá uma criança aqui?... si eli vem di longi? $(\mathrm{S}-18 \mathrm{~b})$

A análise das construções reais e eventuais não se esgota no domínio semântico, visto que essas condicionais participam do processo de argumentação, como se verá na próxima seção deste texto. 


\section{Celso Massato Kobashi}

2. Discursivização das construções condicionais

No campo discursivo, quatro questões põem em destaque as construções condicionais: (1) a articulação tópico / foco; (2) as condicionais de ato de fala; (3) as condicionais como instrumento de argumentação e (4) os processos de realce.

\subsection{A articulação tópico / foco}

Haiman (apud Neves, 1999) considera as orações condicionais antepostas como tópicos dos períodos em que se encontram. Elas formam uma "moldura de referência" para o que será dito na oração principal, que contém o foco, ou informação nova.

Um fato que contribui para a aproximação entre os tópicos e as prótases é a grande similaridade entre estas e as perguntas polares. Tais perguntas instauram uma espécie de miniconversação, na qual o falante propõe uma questão e obtém o consentimento implícito do seu interlocutor, e esse consentimento serve de base (ou referência) ao que o falante dirá logo em seguida. Seja o exemplo:

(35) robô? ... pega essi danadu leva pra lá... meti lá dentru daqueli muru imensu lá com uma correnti nu pé qui nem era antigamenti... vai trabalhá... si matô vai trabalhá si robô vai trabalhá ninguém ia fazê... mai não... (S-18b)
A: Matou? Roubou?
B: (Sim)
A: (Então) vai trabalhar

O mesmo raciocínio pode ser utilizado para casos em que a contraparte envolve uma negativa ou uma dúvida. Exemplos:

(36) Inf eu detestu morá im favela... si fossi pur mim... si eu tivessi trabalhandu... ganhandu ( $)$ eu tava longi daqui $(4-4 a)$

A: Eu estou trabalhando / ganhando?

B: (não)

A: (Então) eu não estou longe daqui 
(37) aí eu falei “ah... si pudé a genti vai né?”...(1 - 1a)
A: A gente pode ir?
B: (talvez)
A: (Então) (em caso de concordância) a gente vai
(Então) (em caso de discordância) a gente não vai

\subsection{As condicionais de ato de fala}

O terceiro tipo de construções condicionais proposto por Sweetser são as condicionais de ato de fala. Nessas construções, o que está expresso na prótase influencia, possibilita ou causa a realização de um ato de fala, que vai expresso na apódose. Podem ser parafraseadas como "se p, eu afirmo/declaro/ pergunto q". Exemplos:

(38) Doc o senhor acha qui u governu tem força pra fazê isso? / Inf u governu?... i quem é qui tem si não sê u guvernu?... só podi é tê purqui si u governu num tivé ié eu qui vô tê? $(\mathrm{S}-18 \mathrm{~b})$

(39) qui meu primu sempri mi deu conselhu... pa nunca casá né?... intão eu falava pra eli “comu qui eu num vô casá... si tendu u pai qui eu tenhu?”... (4 $-4 a)$

(40) melhorô bastante graças a deus... DEUS ME LIVRE se aqui não tivesse luiz... já pensô? $(\mathrm{R}-18 \mathrm{a})$

Na primeira sentença de (38), o falante lança mão de um questionamento para reafirmar a sua convicção de que "só o governo tem força”, e na improvável hipótese de o governo não ter força, ele questiona se ele (falante) é que teria.

Em (39) entende-se que "se é fato que eu tenho o pai que tenho, eu pergunto como eu não vou casar?"

Em (40) "só de pensar na hipótese de que aqui não tivesse luz, eu exclamo deus me livre!" 
Neves (1999) observa que casos como (38-40) demonstram que as condicionais de ato de fala não se restringem apenas às frases de polidez como no exemplo: "Se é que eu posso perguntar, por que você fez iisso?".

Em linhas gerais, as condicionais de ato de fala corroboram a tese defendida por Haiman, de que as condicionais são tópicos e servem como "moldura de referência" ao que vai ser dito na oração núcleo, embora Sweetser não aceite a associação pura e simples entre condicionais e tópicos ${ }^{3}$

2.3 As condicionais como instrumento de argumentação

No corpus analisado, três são os principais contextos que favorecem o emprego das construções condicionais em processos argumentativos:

1) Exemplificação:

(41) qué dizê qui a genti num constrói aqui pur causa dissu... i u u u... pur exemplu...

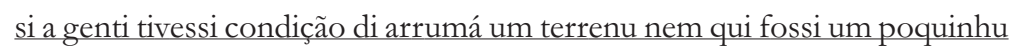
longi eu tinha (comprado) né?....(E - 11 a)

(42) então eu falo assim né? se a pessoa por ixemplu si a pessoa... começô a í numa igreja di crenti ele sentiu uma melhora ele vai... $(\mathrm{R}-18 \mathrm{a})$

(43) Inf purque si eli manda fazê lá pur ixemplu... eli vai comprá aquela peça qui nóis temu na oficina di reserva nu istoqui vamu supô né? eli vai pagá u DObru... u tantu qui eli vai pagá... compensa u mecânicu deli í lá (b - 23 b)

(44) Inf purque qui si vamu supố... um fala você as veis tem cunfianca nela otra já fala qui ela num presta... otra lá adianti já tá metenu a faca você num podi tê amizadi cum uma pessoa assim / Doc é verdadi $(\mathrm{T}-19 \mathrm{a})$

Gryner (mimeo) destaca que a exemplificação veicula uma ilustração, um exemplo propriamente dito, que serve de evidência em favor do ponto de vista do argumentador. Nas ocorrências acima, os falantes buscam a concordância do interlocutor, através do marcador "né". Em (44), não há o marcador, mas o interlocutor assente logo em seguida ("é verdade").

3 Ver discussão sobre o tema em Neves (1999, p. 502-504.) 
2) os períodos hipotéticos, antecedidos da conjunção porque, são utilizados para expressar uma causa que justifica uma atitude do falante:

(45) a genti num vai muitu pra num atrapalhá eli purque si eli num fô nu otu dia eli perdi a genti não né?... (E -11a)

(46) eu toda vida se eu tenho que fazê uma coisa assim no intervalo do dia, eu levanto cedo pra mim fazê cedo porque se o sol esquentá cedo, depois se complica pra gente né? (D - 11a)

(47) é assim a mema coisa tô na igreja né? agora eu já tô batizada eu não vô desviá porque se eu desviá... aquilu vai voltá tudu di novu volta porque deus pirmiti... $(\mathrm{R}-18 \mathrm{a})$

3) Retomando a concepção lógico-semântica das condicionais, Neves (1999) afirma que as condicionais reais / factuais expressam uma relação condição preencbida - consequência / conclusão, o que as situa num cruzamento entre "condicional" e "causal". Prova disso é que o se pode ser substituído, sem alterações semânticas essenciais, pelo conector causal já que:

(48) óia eu num achu qui:... u lugá u lugá faiz a própia pessoa qui faiz u lugá... si a sinhora si [já que] a sinhora vai im má compania... a sinhora um dia ou vai pricisá matá ou vai pricisá morrê... é issu... si [já que] eu num andu nu meiu delis... eu num tenhu u qui dizê delis nem elis nem sim nem não né? (P 17a)

(10) na primera veiz cê fala "ó... si [já que] num qué mi obedecê podi sumí cum teus amigu...

(49) a pessoa tem... vinte o trinta o quarenta o cinqüenta milhões o qui tantu qui fô... si [já que] é deli muntá uma fábrica... si [já que] é deli comprá uma fazenda... pa tocá agriculturia... tocá a aguapecuária... o indústria o qui fô aqueli dinheru vai pra lá... $(\mathrm{S}-18 \mathrm{~b})$

O complexo condicional real, por enunciar uma relação condição preenchida - consequência / conclusão é utilizado em processos argumentativos nos quais seja necessária ou conveniente a presença de um fato assegurado. Para tanto, marcadores como então destacam o período em bloco como argumento: 
(50) Inf é... fechadinhu é... intão si si uma criança grita (num nivil) mais altu... du otu ladu iscuta tudu... (D - 10b)

(51) intão si adueci... o você o quera o num quera tem qui levá nu médicu... tem qui ficá cum elis im casa dois dia... (T - 19a)

Entre as construções eventuais / potenciais, os períodos condicionais podem funcionar como uma conclusão de uma parte anterior do diálogo:

(52) di manera qui si amanhã o dipois eli quisé prestá uma facudadi eli podi né?. $(X-21 a)$

(53) i comu Eli devi tê muita genti qui faiz assim pur issu qui a pessoa si senti rebaxada... intão si um dia uma impregada doméstica chegá... a ovi u... u qui eu tô diZEnu... num si invergonha nunca di sê UMA impregada domésti$\underline{\text { ca... }}(\mathrm{X}-21 \mathrm{a})$

Nas ocorrências (52-53), os marcadores "de maneira que" e "então" também destacam os períodos condicionais como um bloco argumentativo, da mesma forma que acontece em (50-51).

2.4 Mecanismos de realce

Leão (1961) aponta alguns mecanismos que podem realçar a relação entre a prótase e a apódose. São eles:

\section{1) SE... ENTÂO}

(54) vamu supô si quebra um carru lá im riberão pretu u caminhão da firma né? vamu supô assim... intão eu saiu da oficina central qui tem im são paulu i vô socorrê eli lá $(b-23 b)$

(55) eu dissi assim "não sinhô... num vô mais não"... assim... "ah intão si num vai istudá... intão cê vai pa roça trabaiá" "tudu bem” (V - 20a)

(56) si eli qué assim então é a vontadi deli nu é a minha vontadi é a vontadi deli... nu é a vontadi dus homi... issu aí nu é a vontadi dus homi a vontade é di 
deus purque si... si a minha situação é esta então eu vô cumprí a minha situação $(\mathrm{O}-7 \mathrm{~b})$

$\mathrm{Na}$ língua popular, ocorre a construção equivalente SE... AÌ:

(57) si elis dé a genti... liberá u terrenu aqui pra genti... pa... pagá uma taxazinha pur meis... ou coisa $i$ tal assim... bom a genti firma aqui... si num dé... aí eu intregu pa deus... vê u qui qui deus... podi fazê cum a genti né? (F - 12a)

(58) agora... si eli tivessi... uma boa conta nu bancu... uma boa casa pa morá aí us filhu tava tudu lá “ah meu PAI: essi é meu PAI:”... (P - 17a)

(59) agora si eu... agora agora si eu si eu fossi eu qui fizessi... aí era outra coisa... certu? $(\mathrm{D}-24 \mathrm{~b})$

(60) quinta-fera qui vem... da otra semana... si dé certu aí eu vô ( ) cum tudu mundu... $(\mathrm{C}-9 \mathrm{~b})$

Leão (1961, p. 101), assim explica o uso dessa correlação:

A correlação hipotética, que existe logicamente, costuma resolver-se na língua por uma estrutura de subordinação. Entretanto, o falante sente, às vezes, necessidade de pôr em maior evidência a relação entre os dois fatos por uma estrutura que lembre de perto a correlação lógica, isto é, com presença de dois termos correlativos. O Português recorre a "se...então"

2) SE ... É (ERA, FOI, ETC)

(11) si você já Pois ali na crechi é purque num tem quem fiqui

Do ponto de vista discursivo, esta construção de "Se... é" põe em destaque a causa (porque), que vem logo após o verbo ser.

\section{3) SE CASO ou SE POR ACASO}

Em construções desse tipo, reforça-se ainda mais o valor de hipótese:

(61) pa vê comu é qui é... i... i si... i si pur acasu vê... si dava pa vivê si dava pa vivê eu ficava... sinão eu voltava né?... ( V - 20a) 
(62) já volta juntu i vem fazendu assistência nu carru si casu dé um detalhi nu caminhu $(b-23 b)$

Considerações finais

Neste trabalho, analisei de forma qualitativa os processos de semanticização e discursivização das construções condicionais no português popular falado na cidade de São Paulo.

A articulação de orações - expressa na formulação lógica $S E p$, (então) $q$ - resulta em três tipos básicos de construções condicionais: reais / factuais, irreais / contrafactuais e eventuais / potenciais. Dentro de cada uma delas, é possível depreender uma variada gama de nuances semânticas.

As construções eventuais são as mais profícuas: nelas, se expressam as nuances de implicação, habitualidade, oposição e / ou concessão, ressalva, condição necessária e suficiente, e "lembrete" (afterthought)

Nas reais, encontram-se os valores implicativo (que é do tipo "causa conseqência"), epistêmico (conclusão), habitual e opositivo e / ou concessivo.

As irreais são do tipo implicativo. A esse grupo pertencem também as orações de COMO SE.

No campo discursivo, as condicionais se destacam na semelhança entre prótases e tópicos, nas construções "de ato de fala", em processos argumentativos e de realce.

Este trabalho é, em síntese, um breve panorama da realização efetiva das construções condicionais no português popular paulistano.

Referências bibliográficas

CASTILHO, Atáliba T. de (2010). Nova Gramática do Português Brasileiro. São Paulo, Contexto. GERALDI, J. W. (1978) Se a semântica fosse também pragmática... ou para uma análise semântica dos enunciados condicionais. (Mestrado). Campinas, Unicamp.

GRYNER, Helena. Variação modal como estratégia argumentativa. Mimeo.

KOBASHI, Celso Massato. (2004) Lingua Falada - A Ordem Das Oraçoes No Período Condicional No Português Popular Brasileiro: Implicações Semânticas EGramaticalização. Dissertação de Mestrado. São Paulo, USP.

LEÃO, Ângela Vaz. (1961) O Período Hipotético Iniciado Por Se. Belo Horizonte, Universidade de Minas Gerais. 
MIRA MATEUS, Maria Helena et alli. (1983) Gramática da Lingua Portuguesa. Coimbra, Almedina. NEVES, Maria Helena Moura (1999) “As construções condicionais". In: NEVES, M.H.N. (org.) Gramática do Português Falado. V. VII: Novos estudos. São Paulo, Humanitas/FFLCH/ USP; Campinas, Editora da Unicamp. p. 397-444.

NEVES, Maria Helena Moura (2000) "As conjunções condicionais. As construções condicionais". In Gramática de Usos do Português. São Paulo, Unesp, p. 129-161.

Recebido em: 05/dez./2010

Aprovado em: 05/mai./2011 